\title{
Minority Identification Project Goes Online
}

APSA is pleased to announce that the Minority Identification Project (MID) is now online. A collaboration of undergraduate and graduate political science programs, the MID was created with the goal of attracting talented minority undergraduate students to graduate study in political science and, ultimately, to increase diversity in the political science profession.

Making it possible to submit and review promising students' information online should greatly improve an already successful program. Undergraduate faculty must still talk with their students about professional careers in political science and the graduate school experience and submit interested students' names and scholastic information to APSA. But the resulting data will be entered via the web, and will be more complete and easier to update and search. Representatives of core graduate schools will have access to the online student profiles and will be encouraged to download information from the database and recruit potential applicants.

Any undergraduate institution can submit names at no cost, but only recruiters at core graduate schools will be allowed to search the MID candidate database. To make their institution a core school, school officials must agree to pay an annual fee of $\$ 150$ to cover administrative and web costs, submit names of undergraduate minority students to the program, actively recruit students identified through the project, and send a representative to the Minority Identification Project Breakfast at the APSA Annual Meeting. Core school officials must be willing to invite applications from MID students, waive application fees, and offer full funding or fellowships to the MID students they accept.

Established in 1990, the Minority Identification Project has been successful in aiding minority students find placement within graduate programs. Because it is a collaboration between faculty at both undergraduate and graduate institutions, participation by all political scientists is essential. If you are interested in submitting names to MID and your department is a member of APSA's Departmental Services Program, log in to the MID site from the Association's home page using the departments "My APSA" log in information. Those wishing to submit students' information who are at schools not affiliated with APSA should contact Alison MacDonald at amdonald@apsanet.org or 202-4832512. Representatives of graduate programs interested in making their institutions core schools should contact Alison MacDonald or Sue Davis (sdavis@apsanet.org) for more information.

\section{Introducing MyAPSA for Departments}

As part of its expanding online services, APSA introduced MyAPSA for Departments this fall. Designed to provide departments a central location to manage participation in APSA programs and keep abreast of developments of interest to departments of political science, MyAPSA will allow departments to:

- Submit listings for eJobs. Departments will also have access to the year-round candidate database to assist them in filling mid-year position openings.

- Participate in the Minority Identification Project. Departments may submit names of promising undergraduate minority students and participating graduate departments can get the candidates' information. For more information be sure to visit www.apsanet.org/about/ minority/minorityid.cfm

- Submit "People in Political Science" information for PS: Political Science and Politics (e.g., new appointments, promotions, etc).

- Submit their annual list of completed dissertations.

- Submit names of campuswide teaching award winners for recognition by APSA and Pi Sigma Alpha.
- Find details on submitting nominations for APSA dissertation prizes.

In the future, MyAPSA will be employed to collect information for directories and surveys.

\section{How to Access MyAPSA}

From the APSA's home page (http://www.apsanet.org) scroll down to the log in area for MyAPSA. Enter your departmental service member number as your Departmental ID and key in your password. MyAPSA provides a single $\log$ in system, so department representatives need not remember multiple $\log$ ins in order to access all of the Association's online services and information.

MyAPSA is for members of APSA's Departmental Services Program. The program provides departments and faculty with information they can use for their continuing professional development in organizing courses and counseling students. Not a member? Encourage your department to join. You will find a long list of benefits at: www.

apsanet.org/about/depmemben.cfm

Any questions regarding MyAPSA can be directed to Sean Twombly at twombly@apsanet.org. Questions regarding eJobs or the MID project should be directed to the appropriate address_minority@apsanet.org or ejobs@apsanet.org. 